\title{
ENSINO TÉCNICO EM MÚSICA NO ESTADO DE SÃO PAULO: UMA DÉCADA DE EDUCAÇÃO PÚBLICA NA ESCOLA TÉCNICA ESTADUAL "JACINTO FERREIRA DE SÁ" 1
}

\author{
Paulo Constantino \\ CPS/UNESP/Universidade Aberta de Portugal \\ pconst2@gmail.com
}

\begin{abstract}
RESUMO
Relato o percurso de uma década (2007-2017) da implantação e oferta dos cursos técnicos da área de música na Escola Técnica Estadual Jacinto Ferreira de Sá em Ourinhos, São Paulo, pioneira neste tipo de oferta na educação profissional paulista. Circunscrevo este texto, portanto, ao âmbito da história das instituições escolares e dos espaços formais de educação profissional pública, como uma pequena contribuição para a análise das políticas públicas e as dimensões do atendimento educacional no período, cuja pertinência emerge na demarcação de uma década da música na educação básica nacional, por meio da Lei Federal nº 11769/2008 e suas posteriores modificações.
\end{abstract}

Palavras-chave: História da educação. Educação musical. Educação profissional.

\section{VOCATIONAL EDUCATION IN MUSIC: A DECADE OF PUBLIC EDUCATION AT THE STATE TECHNICAL SCHOOL “JACINTO FERREIRA DE SÁ” IN OURINHOS, BRAZIL}

\begin{abstract}
The text reports the course of a decade (2007-2017) of the foundation of technical courses in the music area at the State Technical School Jacinto Ferreira de Sá (Etec) in Ourinhos, São Paulo, Brazil, pioneer in this offer in vocational education in São Paulo. I thus circumscribe this text to the scope of the history of institutions and the formal spaces of public vocational education as a small contribution to the analysis of public policies and the dimensions in the period, whose pertinence emerges in the demarcation of a decade of music in national basic education, through Federal Law 11769/2008 and its subsequent modifications.
\end{abstract}

Keywords: History of education. Music education. Vocational education.

\section{LA ENSEÑANZA TÉCNICA EN MÚSICA: 10 AÑOS DE EDUCACIÓN PÚBLICA EN LA ESCUELA TÉCNICA ESTATAL JACINTO FERREIRA DE SÁ - OURINHOS, BRAZIL}

\section{RESUMEN}

Presenta el relato en el marco de una década (2007-2017) de la implantación y oferta de los cursos técnicos del área de música en la Escuela Técnica Estatal Jacinto Ferreira de Sá en Ourinhos, São Paulo, Brasil, pionera en este tipo de oferta en la educación profesional. En el marco de la historia de las instituciones escolares y de los espacios formales de educación profesional pública, circunscribo este texto, como una pequeña contribución para el análisis de

\footnotetext{
${ }^{1}$ Um resumo da versão preliminar deste texto foi comunicado durante a Jornada Patrimônio Cultural e Tecnológico da Educação Profissional, Centro Paula Souza, São Paulo, nos dias 09 e 10 de novembro de 2017.
} 
las políticas públicas y las dimensiones de la atención educativa en el período, cuya pertinencia emerge en la demarcación de una década de música en la educación básica nacional, por medio de la Ley Federal nº 11769/2008 y sus posteriores modificaciones.

Palabras clave: Historia de la educación. Educación musical. Educación profesional.

\section{L'ENSEIGNEMENT TECHNIQUE EN MUSIQUE: 10 ANS CHEZ L'ÉCOLE TECHNIQUE ETEC JACINTO FERREIRA DE SÁ - OURINHOS, SÃO PAULO, BRAZIL}

\section{RÉSUMÉ}

Je rapporte le déroulement d'une décennie (2007-2017) de l'implantation et de l'offre des cours techniques du secteur musical à l'école technique Jacinto Ferreira de Sá, Ourinhos, São Paulo, Brazil, pionnier dans ce type d'offre de formation professionnelle à São Paulo. Je circonscrit ainsi ce texte à la portée de l'histoire des institutions scolaires et des espaces formels de l'enseignement professionnel public en tant que petite contribution à l'analyse des politiques publiques et aux dimensions du service éducatif de l'époque, dont la pertinence la musique dans l'éducation, par la loi fédérale 11769/2008 et ses modifications ultérieures.

Mots-clés: Histoire de l'éducation. Education musicale. Formation professionnelle.

\section{INTRODUÇÃO}

O presente texto relata o percurso de dez anos (2007-2017) da implantação e oferta dos cursos técnicos da área de música na Escola Técnica Estadual Jacinto Ferreira de Sá, em Ourinhos, São Paulo, como uma contribuição para a análise das políticas públicas e as dimensões do atendimento educacional no período.

Circunscrevo este texto ao âmbito da história das instituições escolares (SAVIANI, 2005) e dos espaços formais de educação profissional pública no Estado de São Paulo. Sua relevância reside no fato de registrar os dez primeiros anos do que seria o primeiro curso técnico em música oferecido pelas Escolas Técnicas Estaduais paulistas, ligadas ao Centro Paula Souza, uma entidade autárquica responsável pela educação profissional pública no Estado. Foi também a primeira iniciativa de oferta de ensino profissionalizante em São Paulo não necessariamente ligada às Universidades paulistas (a Unicamp, por exemplo, já possuía cursos profissionalizantes), escolas livres ou tradicionais conservatórios como o 'Conservatório Dramático e Musical Dr. Carlos de Campos’ de Tatuí.

Se é verdade que a história da educação musical no Brasil ainda é um campo em construção (SOUZA, 2014; FUCCI-AMATO, 2006, 2012), tal como a história da educação profissional (CARVALHO, 2011), com uma cultura de investigação sistemática que não possui mais do que um terço de século, por outro lado, a presença da música nas escolas públicas 
paulistas tem sido recorrente: relatos do período do Império demonstram que era considerada fundamental para uma formação educacional completa (NOGUEIRA, 2001, p. 301), o que se estenderia também para o período da Primeira República, em 1892 (VIDAL; FARIA FILHO, 2005, p.43). Atentar para a música nas escolas, trata-se, portanto, de uma espécie de cultura escolar paulista, presente desde seus primeiros momentos.

O breve relato, suportado por uma pesquisa documental (TOZONI-REIS, 2010), encontra um paralelo temporal nas transformações sofridas pelo contexto legal da educação musical brasileira: há uma década, viu-se a aprovação da Lei Federal no 11.769/2008, que instituiu a Música como conteúdo obrigatório em toda educação básica. A Lei 11.769/2008 acabou suplantada pela Lei $\mathrm{n}^{\circ}$ 13.278/2016 (BRASIL, 2016a), sancionada em maio de 2016, que emendou a Lei de Diretrizes e Bases da educação nacional: onde lia-se que a música deveria "ser conteúdo obrigatório, mas não exclusivo" (BRASIL, 2008a, s.n), passou a vigorar o novo texto afirmando que as "artes visuais, a dança, a música e o teatro são as linguagens que constituirão o componente curricular" (BRASIL, 2016a, s.n) Arte em toda educação básica, do ensino infantil ao médio. Recordo também as Diretrizes Curriculares para a Operacionalização do Ensino de Música na Educação Básica (BRASIL, 2016b), que procuravam orientar a implementação e oferta de "cursos técnicos de nível médio na área da Música pelos Institutos Federais de Educação, Ciência e Tecnologia e demais instituições de Educação Profissional e Tecnológica" (BRASIL, 2016b, p. 10).

O exame da literatura também aponta para a necessidade permanente de discussão desta modalidade de formação, pois em pleno século XXI ainda se tem no Brasil um contexto instável, de acordo com Costa (2012), caracterizado pela conjunção da:

[...] permanência do modelo conservatorial, instituído no século XVIII, baseado na reprodução de música erudita e escrita, direcionado à carreira solista virtuosística, para a qual se conjuga um determinado tipo de ensino, o discurso da cidadania e da autonomia na formação para o trabalho, presente na legislação pertinente à educação profissional, a grande procura por "cursos livres", o alto índice de evasão, o baixo número de formandos nos cursos técnicos e a expressiva procura por ingresso nas instituições especializadas. Convive-se com o desconhecimento das intenções dos alunos em formação e com a desconexão frente às possibilidades de inserção laboral, crivada por forte reestruturação produtiva no trabalho formal em música. (COSTA, 2012, p. 104).

Posto isto, o recorte específico sobre a unidade escolar oferece uma contribuição para um campo que, reconhecidamente, apresenta escassa bibliografia no país, ao considerarmos o contexto da educação musical associado à memória da educação profissional. 


\section{CARACTERIZAÇÃO DA INSTITUIÇÃO E DO CURSO}

Quanto à caracterização da instituição pública relatada, o Centro Estadual de Educação Tecnológica Paula Souza, ou Centro Paula Souza, informe-se que iniciou suas atividades em 06 de outubro de 1969, como uma entidade autárquica destinada a articular e desenvolver a educação técnica e tecnológica de nível médio e superior no Estado de São Paulo. Atualmente ligada à Secretaria do Desenvolvimento Econômico, Ciência, Tecnologia e Inovação, mantém 220 Escolas Técnicas (Etecs) e 66 Faculdades de Tecnologia (Fatecs) em funcionamento em mais de 300 municípios do Estado. Somente no Ensino Médio e Técnico, em setores e eixos tecnológicos diversificados entre os de serviços, indústria, saúde e a produção cultural, o número de alunos matriculados ultrapassou 208 mil em diferentes habilitações no primeiro semestre de 2017, conforme informação da Unidade de Ensino Médio e Técnico da instituição em seu sítio (CPS, 2017).

Apesar deste histórico do Centro Paula Souza na educação profissional em diferentes eixos tecnológicos, somente quatro décadas mais tarde, em 2007, uma destas escolas, localizada no interior do Estado, se incumbiria de implantar o primeiro curso técnico da área de música na instituição, o que ocorreu na Etec Jacinto Ferreira de Sá, em Ourinhos, no oeste paulista.

A escola foi fundada em 23 de julho de 1970 com o nome de 'Colégio Técnico Industrial Estadual de Ourinhos', sendo mantida pelo Governo do Estado de São Paulo desde seus primórdios. Os primeiros cursos oferecidos eram as habilitações profissionais de Técnico em Economia Doméstica, Edificações, Eletromecânica e Mecânica. Em 1984, a unidade passou a ser administrada pelo Centro Estadual de Educação Tecnológica Paula Souza. Em 2007, ano em que iniciou o curso Técnico em Música, contava com 870 alunos em suas diferentes habilitações, incluindo-se o Ensino Médio. 
Figura 1: Fachada da Etec Jacinto Ferreira de Sá em Ourinhos/SP.

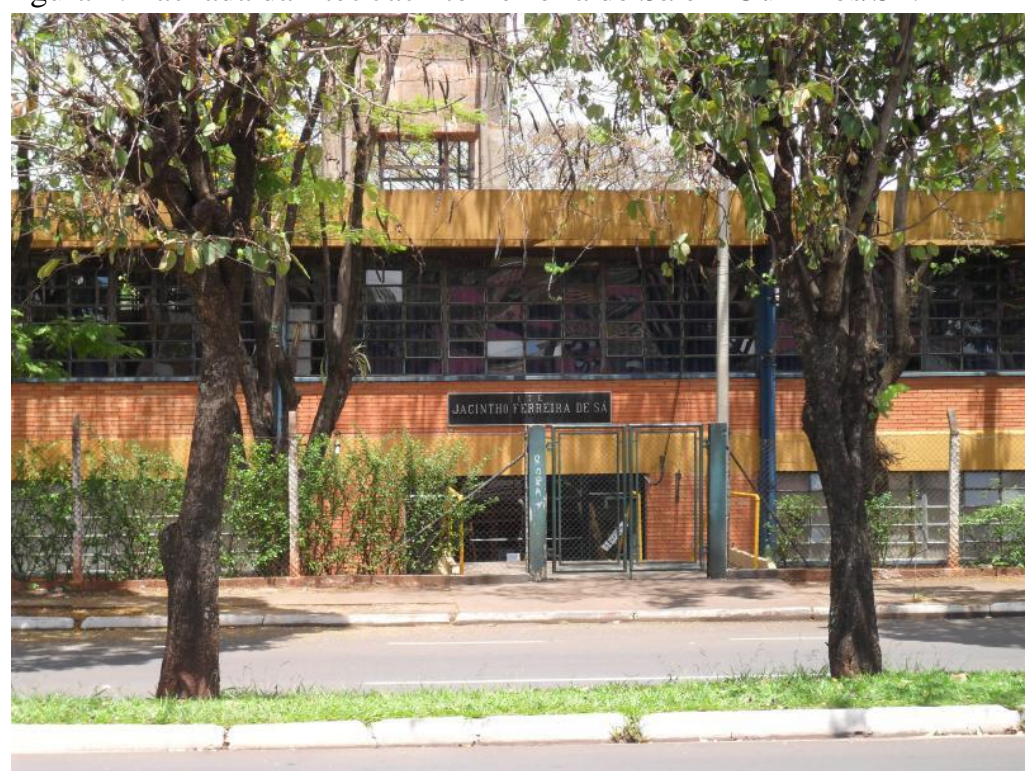

Fonte: Plano Escolar da unidade. Disponível em: www.cpscetec.com.br/planoescolar/

Em 2016, a Etec Jacinto Ferreira de Sá oferecia, além dos Técnicos em Regência e Canto, os cursos de Técnico em Açúcar e Álcool, Edificações, Enfermagem, Informática, Informática para Internet, Manutenção e Suporte em Informática, Redes de Computadores, Mecânica, Eletrônica, Eletrotécnica, Química, Administração, Contabilidade, Finanças, Recursos Humanos e Segurança do Trabalho, e três turmas de Ensino Médio, com cerca de 1180 alunos matriculados nestes cursos. Contava com um quadro de 100 professores, 20 funcionários administrativos, 5 estagiários e 22 colaboradores terceirizados (CETEC, 2016).

Inicialmente em 2007, a oferta do curso de música ocorreu por meio de um convênio entre o Centro Paula Souza e a Prefeitura Municipal de Ourinhos, e previa o uso do Centro Cultural da cidade, que possuía equipamentos e a tradição de organizar eventos e festivais na área de música e dança desde o final dos anos de 1990. A direção da Etec estava a cargo do professor Akira Okasaki, que foi um entusiasta da ideia do curso, o que possibilitou segurança na implantação pelos participantes e bom trânsito da escola junto ao poder público local e estadual. Nos anos seguintes (2010-atual), a direção da unidade permaneceria sob responsabilidade do professor Manoel Rodrigues do Carmo Júnior, que igualmente suportou os cursos de música na escola.

O curso Técnico em Música, primeiro curso a ser oferecido, era uma modalidade experimental, e teve sua primeira proposta curricular formatada, à época, por diferentes agentes, como o professor Almério Melquíades de Araújo - Coordenador de Ensino Técnico do Centro Paula Souza; Andréa de Oliveira da Silva Hirga, Coordenadora Pedagógica da Escola de Música do Centro Cultural de Ourinhos; Cláudia Regina Fernandes, diretora de serviços da Etec 
Jacinto Ferreira de Sá; Enrique Briozzo Gibert, Assessor do Conservatório Dramático e Musical - SP; Júlio da Cruz Navega, Diretor do Conservatório Dramático e Musical - SP; Maria Madalena R. Bittencourt, então professora Escola de Música do Centro Cultural de Ourinhos; Robson Marchesani, Diretor da Escola de Música do Centro Cultural de Ourinhos; Fernanda Mello Demai, Assistente Técnico de Direção no CPS e Geraldo B. Serra, da Etec Jacinto Ferreira de Sá - Ourinhos. Tratava-se de um currículo amplo, em três semestres, que dispunha de disciplinas como Execução de Canto e Piano ou Violão; Projetos de atividades de ensino de música; Canto coral e regência; Estruturação musical e harmonia e Gestão de projetos e produção de espetáculos.

Esta primeira proposta curricular foi fortemente marcada pelo desenho de um certo perfil do aluno egresso, comum a outros cursos técnicos reformulados no início dos anos 2000 e caracterizado por Raquel Carmona (2012) como artista músico:

\begin{abstract}
Embora haja reconhecimento na legislação de que o "artista músico" já se faz presente entre muitos profissionais da música que atuam como autônomos, ou freelancers, uma vez que eles já utilizam equipamentos tecnológicos em suas atividades profissionais, criam novas formas e espaços de atuação, demonstram diversidade, fica claro que esse perfil de músico precisa ser trabalhado na formação profissional técnica. Diante de diversos veículos midiáticos atuais como o rádio, a televisão, o cinema, a internet, entendeu-se como imprescindível que os cursos de formação profissional técnica atentassem para essa realidade e procurassem aproximar as propostas pedagógicas às demandas no mercado de trabalho na atualidade. (CARMONA, 2012, p. 545).
\end{abstract}

Elementos para além das habilidades exclusivamente dedicadas à performance musical, tais como "[...] a administração em artes, a produção em arte, a inserção das práticas artísticas em projetos integrados, os multimeios e as multimídias, a conservação de bens culturais, entre outros [...]" (NASCIMENTO, 2003, p. 74) eram contemplados nesta primeira proposta curricular.

O ingresso dos candidatos no curso Técnico em Música, desde o primeiro semestre de 2007, sempre se deu por meio de provas de habilidades específicas, que demandavam os conhecimentos essenciais de música dos alunos, associadas ao processo Vestibulinho de conhecimentos gerais, comum aos demais cursos do Centro Paula Souza em todo o Estado. Pela ordem, o requisito mínimo era que os candidatos tivessem concluído, ao menos, a primeira série do Ensino Médio. O processo de seleção dos candidatos levava em conta uma formação prévia em Música do ingressante, que requeria que o postulante se classificasse entre os 120 primeiros candidatos no processo seletivo geral - Vestibulinho Etec, e fosse examinado em uma prova de conhecimentos específicos em Música, realizada na unidade escolar, em que constavam 50 questões objetivas e uma avaliação prática e individual. 
$\mathrm{O}$ atendimento desenvolvido nestes primeiros momentos não foi apenas útil ao município de Ourinhos, mas um número importante de cidades vizinhas, como Assis, Marília, Palmital, Santa Cruz do Rio Pardo e do norte do Paraná, região fronteiriça e que possui muitos pequenos municípios com tradição em bandas marciais, bandas sinfônicas e centros culturais, que estimularam a atividade musical na região e a presença da música nas escolas. Prova disso é o depoimento de duas alunas oriundas do Estado do Paraná, registrado durante evento realizado na Etec em 2010, que já atuavam como professoras na rede pública regular:

\begin{abstract}
Considerando a nossa atuação na rede pública estadual do Paraná, percebemos que os profissionais que estão atuando no ensino fundamental e médio carecem de uma formação continuada em Música, para subsidiar sua atuação docente. Expostos às recomendações do MEC e diretrizes estaduais - para que sejam proporcionadas aos alunos noções básicas de música, bem como dos cantos cívicos nacionais e dos diversos sons de instrumentos, com o objetivo de permitir as crianças conhecerem a diversidade cultural do Brasil - eles ainda enfrentam dificuldades em sua prática. (Aluna Letícia Borges, do Técnico em Música, em BORGES; LIMA, 2010, p. 09).

Muitas escolas têm dificuldades para desenvolver o trabalho com a música, devido à falta de formação, domínio e habilidade dos professores que atuam na rede, sendo que a maior parte deles tem formação apenas em Artes Plásticas. Ao verificar-se a nossa formação musical pessoal obtida nos cursos de licenciatura em Artes, fez se necessário ampliar os conhecimentos específicos para que as atividades escolares fossem desenvolvidas a contento. Nesse sentido, o curso Técnico em Música, proporcionou um maior aprofundamento no aprendizado e domínio dos conteúdos, atendendo as necessidades encontradas para desenvolver o trabalho com música. (Aluna Luana Lima, do Técnico em Música, em BORGES; LIMA, 2010, p. 09).
\end{abstract}

Considero que o processo educacional desenvolvido no curso Técnico em Música apresentava subsídios para atender a essas necessidades básicas de aprendizagem trazidas pelos alunos das escolas, das igrejas, dos espaços alternativos conhecidos como terceiros ambientes ${ }^{2}$, motivo pelo qual teve boa aceitação durante o primeiro período de sua oferta.

\title{
AVANÇANDO SOBRE A PRIMEIRA DÉCADA DE FUNCIONAMENTO DOS CURSO TÉCNICOS RELACIONADOS À MÚSICA
}

Após funcionar seu primeiro ano dentro do Centro Cultural de Ourinhos, no primeiro semestre de 2008 a habilitação foi movida para o prédio da Etec Jacinto Ferreira de Sá, com os equipamentos e instrumentos musicais próprios da unidade.

\footnotetext{
${ }^{2}$ Os "terceiros ambientes" (HARGREAVES, 2005, p. 09) que não são a escola e nem a casa, por sua própria natureza, não precisam se submeter à legislação ou ao cunho do especialista em educação. Hargreaves se refere aos ambientes extraescolares como sendo "playgrounds, garagens, clubes de jovens ou a própria rua [...], [em que] o fator crucial é a ausência de qualquer atividade formal ou de supervisão por um adulto" (HARGREAVES, 2005, p. 09) ou sujeito, em atividades autoconduzidas.
} 
Figura 2: Duas visões do Centro Cultural de Ourinhos/SP, primeiro local de funcionamento do curso Técnico em Música em 2007.

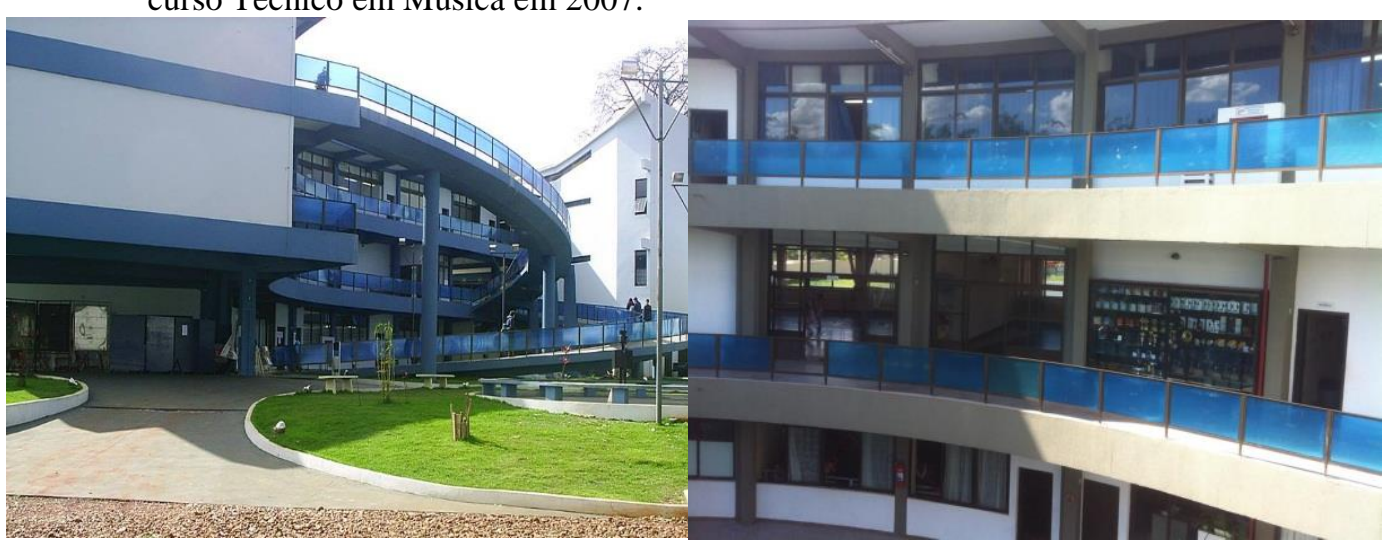

Fonte: Plano Escolar da unidade (CETEC, 2016).

A partir do segundo semestre de 2010, o curso Técnico em Música deixou de ser ofertado, em razão de seu caráter experimental na área de Artes, sendo permutado por novos cursos presentes no Catálogo Nacional de Cursos Técnicos do Ministério da Educação brasileiro: o Técnico em Canto e o Técnico em Regência, dentro do Eixo Tecnológico Produção Cultural e Design (BRASIL, 2008b). Desde aquela década, profissionais e pesquisadores vinham apontando a necessidade de reformulações nos currículos dos cursos técnicos em Música, como destacava Santos (2005, p. 55): "Da formação do profissional da educação infantil e séries iniciais à formação dos formadores, reconstruir a formação dos formadores e fortalecer o profissional [...] é tarefa crucial para este momento".

Portanto, ao analisar as demandas regionais, entendeu-se que o processo educacional do ensino técnico em Música no Centro Paula Souza precisava ser reorganizado, como preconizado por Nascimento (2003),

\footnotetext{
para atender a essas necessidades básicas de aprendizagem comuns a todos os indivíduos e, ao mesmo tempo, garantir uma preparação profissional ajustada às rápidas transformações do mundo do trabalho. Justificam-se, assim, as tentativas de se fazer funcionar uma rede complementar de educação profissional mais flexível e adequada às especificidades cada vez maiores do mercado de trabalho. Nesse sentido, a preparação para uma carreira profissional, devido a esse acelerado desenvolvimento das formas de organização do trabalho, necessita ficar a cargo de espaços e tempos diferenciados, atendendo aos princípios de flexibilidade, multifuncionalidade e laborabilidade. (NASCIMENTO, 2003, p. 71).
}

Entre os coordenadores destes cursos na década, estiveram os professores Daniele Montuleze Seixas (2007), Paulo Roberto Prado Constantino (2008-2010), Marcelo de Souza Franklin Mello (2011-2012) e, nos últimos anos, a professora Maria Madalena Rodrigues Bittencourt (2013-2017), que também foram os professores que iniciaram as atividades ao 
longo de 2007, no núcleo de disciplinas específico da área de Música e Artes. Neste primeiro momento e até meados de 2008, também atuaram os professores Alexandre Mustafa de Moraes e Claudia Mendonça, seguidos pelos professores Hallysson Christyano P. de Oliveira, Gilson Rubens Martins, Juliane do Carmo, Carmen Rosita Constante Moreno, Emerson Carlos Gonçalves e Tatiana Oliveira Andrino. No núcleo comum de disciplinas técnicas da Etec atuaram os professores Carmem Bruder Moraes, Cleusa de Fátima Teixeira Romani, Denílson Furlan, Fábio Nogueira de Queiroz, João Batista Paes e Vera Adriana H. A. Hypólito. O quadro de professores manteve-se, portanto, relativamente estável durante o período analisado.

Figura 3: Do alto e da esquerda para a direita, alunos em apresentações instrumentais e vocais na III Semana de Música da Etec em 2010. Abaixo, práticas de conjunto durante as aulas em 2014 e um concerto temático realizado no auditório da escola em 2016
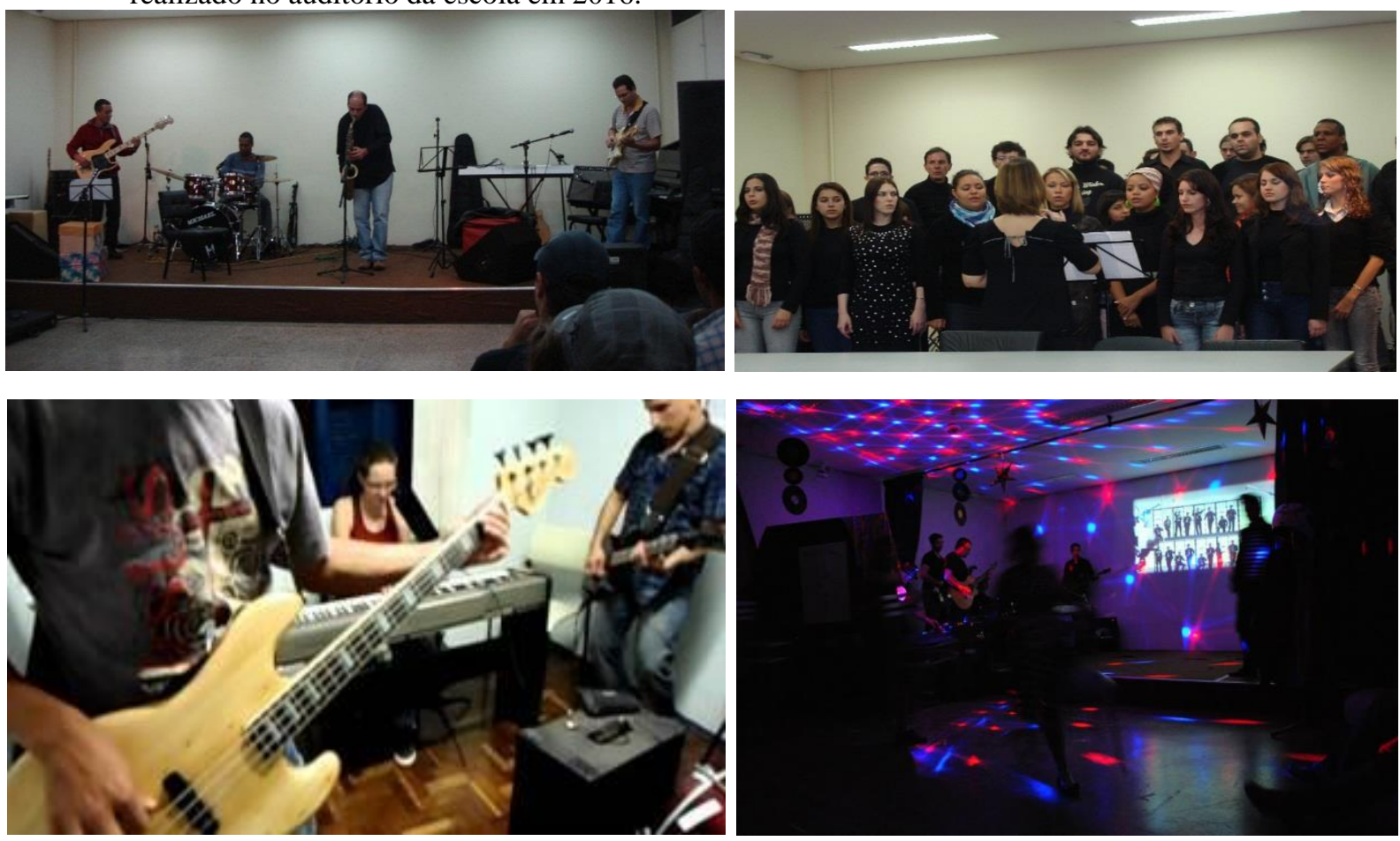

Fonte: acervo pessoal.

Quanto ao atendimento educacional nos últimos 10 anos, entre o primeiro semestre de 2007 e o de 2017, os cursos totalizaram 14 ofertas de turmas com 559 alunos, somando-se os cursos Técnicos em Música (6 turmas), Técnico em Regência (5 turmas) e o Técnico em Canto (3 turmas). Até o segundo semestre de 2016, o total de concluintes foi de 231 alunos, resultando em um índice de 48,2\% sobre o número de matriculados (CETEC, s.d), o que se apresenta como um desafio para este e outros cursos da escola, dados os indicadores de evasão do alunado observados nestes e em outros cursos técnicos da unidade. A situação dos alunos egressos no 
período é outro objeto de pesquisa a ser abordado pelo autor, como oportunidade para futuras investigações.

\section{CONSIDERAÇÕES FINAIS}

A Etec "Jacinto Ferreira de Sá" foi pioneira no Centro Paula Souza ao implantar em 2007 o curso Técnico em Música, uma habilitação técnica em nível médio organizada para o atendimento à clientela de Ourinhos e região - entidades culturais, escolas, igrejas, estúdios que demandavam o profissional na área.

O curso técnico em Música, na ocasião, foi organizado de acordo com os Referenciais Curriculares da Educação Profissional de Nível Técnico, na antiga Área Profissional de Artes e atual eixo de Produção Cultural e Design. Devido à sua vocação eminentemente relacionada à educação e performance musical, desde o início demonstrou forte preocupação com a formação dos profissionais nas atividades de apreciação, performance e composição musical.

Passada uma década, o eixo tecnológico correspondente e a área de Música estão consolidados no Centro Paula Souza. Dentre os desdobramentos importantes da iniciativa de implantação e oferta dos cursos técnicos da área de música na Etec Jacinto Ferreira de Sá, no período compreendido entre 2007 - 2017, destaco que:

a) na esteira do projeto piloto desenvolvido na cidade de Ourinhos em 2007, a capital do Estado de São Paulo ganhou uma unidade escolar inteiramente dedicada aos cursos do eixo tecnológico Produção Cultural e Design: a Etec de Artes. Inaugurada em 13 de maio de 2008, iniciou suas atividades em julho de 2008 com as turmas dos cursos Técnicos em Música e Técnico em Dança. Atualmente funciona em três períodos, ofertando os cursos Técnicos em Canto e Regência (com mais de 320 matriculados em 2016), Arte Dramática, Dança, Teatro, Design de Interiores, Processos Fotográficos, Paisagismo e Eventos (este último, no eixo Turismo, Hospitalidade e Lazer), totalizando 956 alunos no primeiro semestre de 2016 e 920 no segundo, conforme dados obtidos junto ao Banco de Dados da instituição (CETEC, s.d).

b) as duas escolas técnicas estaduais referidas passaram a atuar como instituições certificadoras de competências, em parceria com o Conservatório de Tatuí (no formato de complementação dos estudos livres com a formação técnica em nível médio) ou por meio das solicitações individuais dos interessados que possuam saberes obtidos em campo, conforme previsto na legislação educacional brasileira. Estas instâncias de certificação de competências laborais são parte de uma política educacional mais ampla em diferentes campos do saber, nas esferas estadual e federal, e não apenas na área de Música; 
c) criou-se, em uma região que não possuía nenhuma escola técnica pública oficialmente reconhecida ou mesmo cursos superiores em Música, uma janela de oportunidades de formação musical, que permitiu aos 231 egressos atuarem em diferentes frentes, como escolas, igrejas e associações, estúdios de gravação, concertos e musicais, projetos sociais e educativos públicos ou privados, corais, grupos vocais e de câmara.

d) As condições postas pela antiga lei federal $n^{\circ} 11769 / 2008$ - que instituiu a música como componente obrigatório nos currículos das escolas brasileiras - e a experiência adquirida durante as atividades do curso técnico em Música do Centro Paula Souza, nos permitem projetar e investir na educação profissional também como uma forte aliada das instituições de ensino superior, contribuindo para encaminhar profissionais competentes ao mercado de trabalho e, simultaneamente, um público mais preparado para o prosseguimento na vida acadêmica, sendo ainda uma alternativa para a formação continuada de professores não-especialistas que já atuam no ensino infantil e fundamental paulista. Além disso, poderia somar-se a outras iniciativas, que podem ser igualmente úteis em apoiar a formação e qualificação do quadro de educadores musicais, tais como os cursos de formação continuada para músicos não licenciados ou professores generalistas, cursos semipresenciais e em nível de pós-graduação.

Outros desafios se apresentam particularmente para a Etec Jacinto Ferreira de Sá para os próximos anos, como a redução das taxas de evasão escolar entre os alunos ou o aperfeiçoamento das organizações curriculares dos cursos, ajustando-as às demandas de serviços e culturais próprias do interior paulista. Espero que este registro estimule novas pesquisas relacionadas, por exemplo, aos alunos egressos ou ao perfil dos ingressantes. Também seria útil como registro inicial para outras análises pormenorizadas das políticas públicas de oferta, com vistas à uma necessária ampliação do atendimento em educação profissional nas próximas décadas.

\section{REFERÊNCIAS}

BORGES, Letícia Bueno de Camargo; LIMA, Luana Rodrigues de. Importância do ensino Técnico em Música na formação de arte-educadores. In: ETEC JFS. III SEMANA DE MÚSICA DA ETEC JACINTO FERREIRA DE SÁ. Circulação restrita. Anais [...]. Ourinhos: Não publicado, 2010. p. 09-10.

BRASIL. Congresso Nacional. Lei Complementar $n^{\circ}$ 11.769, de 19 de agosto de 2008. Altera a Lei no 9.394, de 20 de dezembro de 1996, Lei de Diretrizes e Bases da Educação, para dispor sobre a obrigatoriedade do ensino da música na educação básica. Diário Oficial da União. 
Brasília, DF, 2008a. Disponível em: http://www.planalto.gov.br/ccivil_03/_ato20072010/2008/lei/111769.htm. Acesso em: 30 jan. 2016.

BRASIL. MEC. Catálogo Nacional de Cursos Técnicos. Brasília: MEC, 2008b. Disponível em: http://pronatec.mec.gov.br/cnct/. Acesso em: 03 jan. 2017.

BRASIL. Congresso Nacional. Lei n ${ }^{\circ} 13278$, de 02 de maio de 2016 . Altera o $\S 6^{\circ}$ do art. 26 da Lei no 9.394, de 20 de dezembro de 1996, que fixa as diretrizes e bases da educação nacional, referente ao ensino da arte. Diário Oficial da União. Brasília, DF, 2016a. Disponível em: http://www.planalto.gov.br/ccivil_03/_Ato2015-2018/2016/Lei/L13278.htm. Acesso em: 01 jun. 2016.

BRASIL. MEC. Despacho do ministro, n. 86 de 05 de maio de 2016. Homologa o Parecer CNE/CEB no 12, de 04 de dezembro de 2013. Diretrizes nacionais para a operacionalização do ensino de Música na Educação Básica. Diário Oficial da União, 06 de maio de 2016. Brasília, DF, 2016b.

CARMONA, Raquel. Educação profissional técnica de nível médio em música e perfil do egresso: uma visão atual. II SIMPOM. Anais [...] 2012. p. 542-550. Disponível em: http://www.seer.unirio.br/index.php/simpom/article/download/2475/1804. Acesso em: 12 jun. 2017.

CARVALHO, Maria Lúcia Mendes. Cultura, saberes e práticas: memórias e história da educação profissional. São Paulo: Centro Paula Souza, 2011.

CETEC. Plano plurianual de gestão da Etec Jacinto Ferreira de Sá 2016-2020. Circulação restrita, 2016. Disponível em: http://www.cpscetec.com.br/planoescolar/. Acesso em: 12 fev. 2017.

CETEC. Banco de dados da Unidade de Ensino Médio e Técnico do Centro Paula Souza. S.d. Disponível em: http://www.cpscetec.com.br/bdcetec/index.php. Acesso em 12 fev. 2017.

COSTA, Cristina Porto. A formação do técnico em música em nível médio na visão de professores de instrumento musical. Revista da ABEM, v. 20, n. 29, p. 103-115, jul./dez. 2012.

CPS. Perfil e histórico do Centro Paula Souza. Disponível em: http://www.cps.sp.gov.br/quem-somos/perfil-historico/. Acesso em 12 fev. 2017.

FUCCI-AMATO, Rita de Cássia. Escola e educação musical: (des) caminhos históricos e horizontes. Campinas: Papirus, 2012.

FUCCI-AMATO, Rita de Cássia. Breve retrospectiva histórica e desafios do ensino de música na educação básica brasileira. Revista Opus, v. 12, p. 144-166, 2006.

HARGREAVES, David. J. "Within you without you”: música, aprendizagem e identidade. Revista eletrônica de musicologia, v. 9, out. 2005. Disponível em: http://www.rem.ufpr.br/_REM/REMv9-1/hargreaves.html. Acesso em: 28 jul. 2017.

NASCIMENTO, Sônia de Almeida do. Educação profissional - novos paradigmas, novas práticas. In: Revista da ABEM, n. 8. Porto Alegre: ABEM, 2003. p. 69-74. 
NOGUEIRA, Lenita. Waldige Mendes. Música em Campinas nos últimos anos do Império. Campinas: Editora da Unicamp, CMU, 2001.

SANTOS, Regina Marcia Simão. Música, a realidade nas escolas e políticas de formação. Revista da ABEM, n. 12. Porto Alegre: ABEM, 2005. p. 49-56.

SAVIANI, Demerval. Instituições escolares: conceito, história, historiografia e práticas. Cadernos de História da Educação, n. 4, p. 27-33, jan. dez. 2005. Disponível em: http://www.seer.ufu.br/index.php/che/article/view/382/363. Acesso em: 12 fev. 2017.

SOUZA, Jusamara Vieira. Sobre as várias histórias da educação musical no Brasil. Revista da ABEM, Londrina, v. 22, n. 33, p. 109-120, jul./dez. 2014.

TOZONI-REIS, Marília Freitas de Campos. A pesquisa e a produção de conhecimentos. Universidade Estadual Paulista. Prograd. Caderno de formação: formação de professores educação, cultura e desenvolvimento, v. 3. São Paulo: Cultura Acadêmica, 2010. p. 111-147.

VIDAL, Diana Gonçalves; FARIA FILHO, Luciano Mendes de. As lentes da história: estudos de história e historiografia no Brasil. Campinas: Autores Associados, 2005.

Recebido em: 02 de julho de 2018 Aceito em: 21 de dezembro de 2018 